\title{
O Punhobol na cidade do Rio Grande/RS: dos primeiros passos à consolidação como
}

\section{um esporte escolar}

\author{
The Fistball in the city of Rio Grande/RS: from the first steps to consolidation as a school sport
}

El Puñobol en la ciudad de Rio Grande/RS: de los primeros pasos a la consolidación como un deporte escolar

Recebido: 30/12/2021 | Revisado: 04/01/2022 | Aceito: 08/01/2022 | Publicado: 12/01/2022

Leontine Lima dos Santos
ORCID: https://orcid.org/0000-0002-9686-2339
Prefeitura Municipal do Rio Grande, Brasil
E-mail: leontinesantos10@ @mail.com
Leonardo Costa da Cunha
ORCID: https://orcid.org/0000-0002-7719-9260
Instituto Federal de Educação, Ciência e Tecnologia do Rio Grande do Sul, Brasil
E-mail: leonardo.cunha@ riogrande.ifrs.edu.br
Fabiana Celente Montiel
ORCID: https://orcid.org/0000-0002-9921-6703
E-mail: fabianamontiel@ifsul.edu.br

\begin{abstract}
Resumo
O presente artigo objetiva compartilhar a experiência do município do Rio Grande/RS, no que se refere ao registro histórico de implementação, realização e efetivação de ações voltadas ao Punhobol escolar. É um estudo de caráter descritivo, a partir da busca documental contida nas notícias postadas no site da Secretaria de Município da Educação (SMEd) entre os anos de 2013 e 2019. A análise dos dados se deu na perspectiva da análise de conteúdo e resultou em três categorias de análise: Divulgações das ações em Punhobol; Resultados de ações em Punhobol realizadas no município; e Resultados de competições estaduais. Percebe-se o Punhobol presente nas escolas de Rio Grande nas aulas de Educação Física, Projetos Extraclasse e competições esportivas realizadas tanto no município quanto a nível estadual, assim integrando as escolas com outras comunidades, grupos e instituições. Além disso, a organização e participação em eventos esportivos, como os Festivais e Copas, demonstram o quão inserido esse esporte está na Educação Física e na cultura escolar como um todo, o que foi observado pela mobilização de diferentes instituições de ensino participantes nas ações relatadas. Nesse sentido, percebe-se que, apesar de relativamente recente, o trabalho realizado tem feito com que o Punhobol deixe de ser um esporte totalmente desconhecido e se torne uma prática popular em uma parcela considerável de escolas no município do Rio Grande, escrevendo assim, a história de sucesso dessa prática consolidada a nível escolar.
\end{abstract}

Palavras-chave: Punhobol; Esporte; Educação física escolar.

\begin{abstract}
This article aims to share the experience of Rio Grande city, state of RS, with regard to the historical record of implementation, realization and execution of actions aimed at school Fistball. It is a descriptive study, based on the documental research in the news posted on the website of the Municipal Department of Education (SMEd) between the years 2013 and 2019. Data analysis took place from the perspective of content analysis and resulted in three categories of analysis: Disclosures of actions in Fistabll; Results of actions in Fistball carried out in the city; and Results of state competitions. Fistball is present in schools in Rio Grande in physical education classes, extra-class projects and sports competitions held both in the municipality and at the state level, thus integrating schools with other communities, groups and institutions. In addition, the organization and participation in sporting events, such as festivals and cups, shows how into physical education and in school culture as a whole this sport is, fact that was observed by the mobilization of different educational institutions participating in the reported actions. In this sense, it is clear that, despite being relatively recent, the work carried out has made Fistball not being a totally unknown sport anymore and becoming a popular practice in a considerable portion of schools of Rio Grande, writing thus, the success story of this practice consolidated at the school level.
\end{abstract}

Keywords: Fistball; Sport; School physical education. 


\section{Resumen}

El presente artículo tiene como objetivo compartir la experiencia en la ciudad de Rio Grande, Estado de Rio Grande do Sul, Brasil, como un registro histórico de la ejecución de acciones voltadas al Puñobol escolar. Se trata de un estudio de carácter descriptivo, a partir de registros de noticias publicadas en el sitio de la secretaria de Educación de la ciudad, entre los años de 2013 y 2019. El análisis de datos fue hecha a partir de los contenidos y resultó en trés categorias. Divulgación y resultado de las acciones, Resultado de los torneos. Fue constatado que la modalidade deportiva está presente en las Escuelas en las clases, actividades extra curriculares y torneos, estes, inclusive, a nível del Estado. De esta forma, fue percibido que, mismo siendo un trabajo reciente, esa modalidad deportiva, ya hace sentir su presencia en una parcela significativa de las Escuelas de la ciudad.

Palabras clave: Puñobol; Modalidad deportiva; Educación física escolar.

\section{Introdução}

Historicamente a prática do Punhobol é datada em 300 anos a.C., mas é apenas em 1985 que as primeiras regras são publicadas na Alemanha, onde o esporte apresentou maior repercussão. No Brasil essa prática chega, trazida por imigrantes germânicos, por volta de 1906 e se dissemina na Sociedade de Ginástica de Porto Alegre (SOGIPA) para uma parcela restrita de participantes (Silva et al., 2020).

Originalmente chamado de Faustball ou Fistball - em alemão e em inglês, respectivamente - o Punhobol é um esporte coletivo, praticado por duas equipes de cinco jogadores/as, em um campo oficial medindo 50x20 metros, como mostra a figura 1, ou em quadra de 40×20 metros. A área de jogo é dividida por uma rede (fita) de $5 \mathrm{~cm}$, que fica a uma altura de 2 metros para os homens e 1,90 metros para as mulheres. Para as categorias menores é utilizado a altura de 1,80 metro no sub-14 e 1,60 metro para o sub-12 (Jung, 2018).

Figura 1 - Campo de Punhobol e suas dimensões e equipamentos oficiais para os homens.

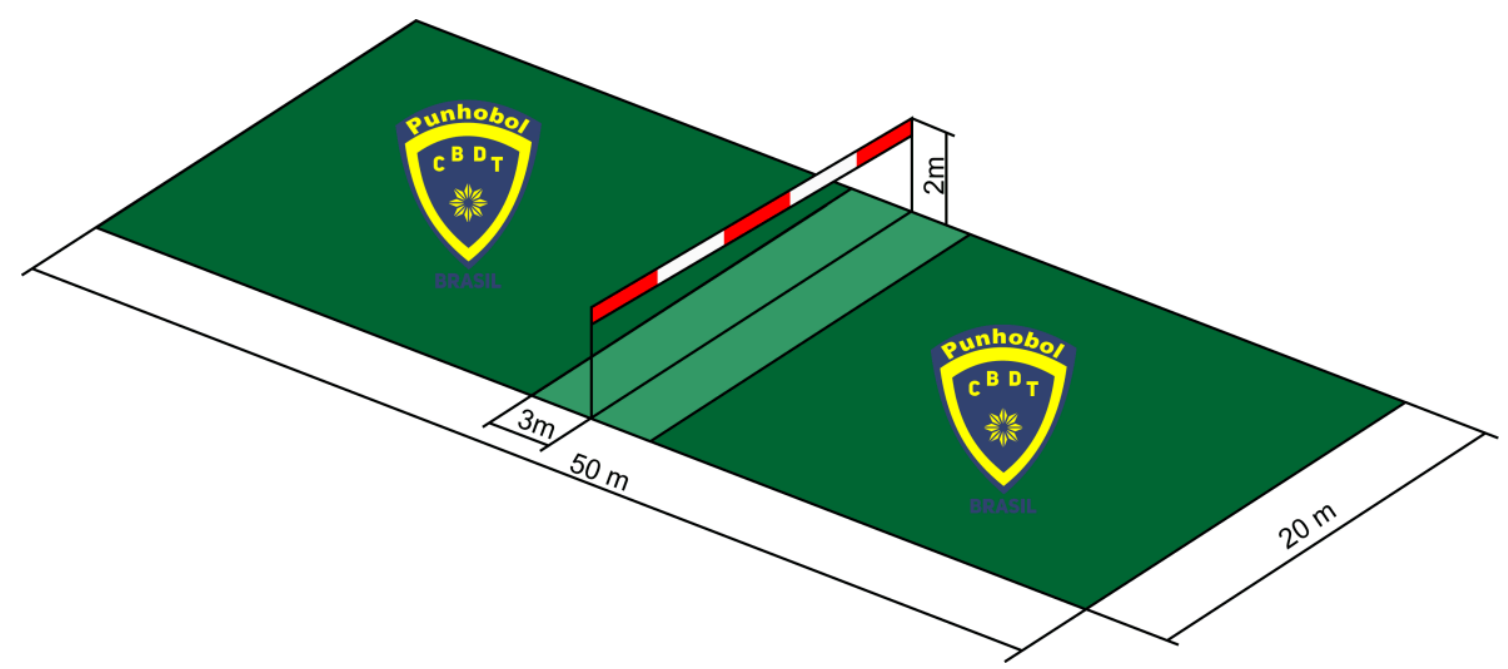

Fonte: https://cbdt.com.br/regras-punhobol/

O objetivo da modalidade é marcar pontos fazendo a bola passar sobre a rede. O jogo começa com um saque, realizado da linha dos 3 metros, o time que recepcionará pode executar até três toques (defesa, levantada e batida), fazendo a bola retornar para o outro lado do campo na tentativa de marcar um ponto. Vale ressaltar que é permitido somente a utilização de um dos braços e o punho fechado. A bola pode tocar em toda a extensão do braço, mas deve ser utilizado, preferencialmente, já que são considerados como movimentos técnicos corretos, o antebraço para a defesa e levantada e obrigatoriamente a mão fechada para a batida e o saque. Essas características da modalidade demonstram a possibilidade inclusão e adaptação dessa modalidade, tanto no âmbito escolar quanto em atividades de lazer (Silva et al., 2020).

A partir da iniciativa de um entusiasta pela a prática do Punhobol em ambiente escolar é que no ano de 2011 esta 
modalidade começa a ser disseminada na região Sul do Rio Grande do Sul (Jung, 2018a; Silva et al., 2020). A realização de um workshop no município de Camaquã foi o marco para o esporte, no qual os/as participantes tiveram a oportunidade de aproximação com a modalidade e, na sequência, levaram a proposição a centenas de estudantes nas diversas cidades da região (SMEd, 2013a).

Objetivamos com este estudo compartilhar a experiência do município do Rio Grande no RS, no que se refere ao registro histórico de implementação, realização e efetivação de ações voltadas ao Punhobol, as quais levaram a uma consolidação da modalidade no ambiente escolar, usando para isso os registros documentais referentes às notícias publicadas no site da Secretaria de Município da Educação (SMEd).

\section{2 - Punhobol, um esporte "Da escola"}

Apesar da presença marcante dos esportes coletivos clássicos no ambiente escolar (voleibol, basquete, futsal, handebol), além de outros não tão conhecidos, mas de possível inserção na escola, entendemos o Punhobol como um esporte que possibilita vivências de cunho pedagógico, principalmente no que diz respeito às suas regras e a fácil adaptação dos espaços e materiais de jogo (Cunha, 2015).

Primeiramente ressaltamos a facilidade de adequação dos espaços para a prática do esporte, que de acordo com Cunha (2015), pode ser vivenciado em lugares abertos ou fechados, em espaços grandes ou pequenos, na grama, na areia mais compactada ou em diferentes tipos de pisos de quadras poliesportivas. Em um segundo momento, vale ressaltar a fácil adaptação dos materiais. Caso não se possua uma bola oficial, o esporte pode ser praticado com qualquer outra bola que quique e seja macia (bolas de voleibol ou de iniciação esportiva, por exemplo). E se não há também a rede (fita) divisória da quadra, pode-se utilizar outros materiais, como cordas e elásticos.

Além disso, é um esporte sem contato físico, o que facilita a prática, num mesmo espaço/tempo de estudantes com estrutura física, gêneros e idades distintas. Outra questão, e talvez a mais importante, é a simplicidade e a facilidade de suas regras, o que permite uma maior participação dos/as estudantes, inclusive daqueles/as considerados/as menos habilidosos/as.

No que tange suas regras, algumas se destacam, caracterizando essa modalidade como uma prática pedagógica e muito pertinente para o espaço escolar. De acordo com Cunha (2015), a característica mais marcante e peculiar do Punhobol, o que deixa o esporte extremamente atrativo para os/as escolares e consequentemente para o ambiente escolar, é a possibilidade do quique da bola. Ou seja, entre cada jogada (defesa, levantada e batida), há a possibilidade, e a permissão, da bola quicar uma vez antes de cada toque (Heck \& Heck, 2014).

É importante ressaltar que o quique não é obrigatório, mas sim uma opção. Contudo, essa possibilidade praticamente garante o sucesso do/a estudante durante o jogo, facilitando o aprendizado e consequentemente sua fluidez, já que o quique possibilita uma reação espaço/temporal, permitindo assim que o/a estudante consiga chegar à bola a tempo de mantê-la em jogo, o que faz do Punhobol um esporte muito pedagógico e lúdico.

Outra regra que chama a atenção, no que tange as questões pedagógicas da prática é a do saque, onde quem tem o direito a executá-lo é o time que sofreu o ponto e não quem fez, fazendo com que uma equipe que seja tecnicamente inferior a outra também consiga participar a todo o momento do jogo, sem ser "massacrada" pela adversária (Cunha, 2015). Além disso, é importante salientar que o saque no Punhobol é executado da linha dos 3 metros e não da linha de fundo, o que facilita e possibilita que os/as estudantes consigam fazer com que a bola chegue ao seu destino, ou seja, o outro lado do campo/quadra. Assim como a possibilidade do quique, essa é outra regra que garante o sucesso dos/as escolares, tornando o esporte dinâmico e atrativo.

Outras regras caracterizam a simplicidade do esporte, e consequentemente o fácil entendimento e dinâmica do jogo no ambiente escolar, como a inexistência de rotação, por exemplo, ou ainda de posicionamentos rígidos em campo/quadra. 
Ademais, se uma equipe efetuar os três toques possíveis na mesma jogada (defesa, levantada e batida), obrigatoriamente três jogadores/as diferentes devem tocar na bola, fazendo com que mais estudantes participem do jogo. Nesse sentido, "tal regra possibilita que, tanto os menos habilidosos participem da jogada, assim como os mais habilidosos não possam se sobressair aos colegas" (Cunha, 2015, p.84). Somado a tudo isso, as formas de pontuar também se caracterizam pela simplicidade.

A disputa em uma partida oficial de Punhobol acontece por sets de 11 pontos, tendo que haver uma vantagem mínima de 2 pontos para fechar o set, com o limite máximo de 15 pontos por set (Heck \& Heck, 2014). Como se trata de um esporte amador, é possível haver, dependendo das competições, adaptações na regra, como disputas de melhor de 5 sets ou de 7 sets, além de jogo por tempo.

Cunha (2015), ainda ressalta que, além das regras, outra vivência experimentada pelos/as praticantes - a saudação ao/à adversário/a - é de extrema importância para a formação do caráter individual, da boa convivência e do respeito com o/a outro/a enquanto coletividade. Nesse momento de saudação, que acontece no início e no final de cada partida, as equipes ficam perfiladas uma de frente para a outra, saudando e cumprimentando os/as adversários/as, seguido pelo nome da escola ou clube ao qual pertencem.

Sendo assim, devido à facilidade de suas regras, somado a fácil adaptação de espaços e materiais para sua prática, nos apropriamos da teoria de Vago (1996) e entendemos que o Punhobol pode ser considerado um esporte "DA escola". Esse também é o entendimento de outros/as professores/as de Educação Física que desenvolvem o Punhobol em suas escolas, como percebemos por meio do estudo de Jung (2018a), ao trazer relatos de docentes ao serem questionados/as sobre o motivo de trabalharem com a modalidade, como segue:

Os alunos se interessam pela facilidade da bola poder quicar"; "O Punhobol é uma modalidade esportiva que trabalha o grupo. Os alunos passaram a ser mais responsáveis, amigos, aprenderam a trabalhar em conjunto, a respeitar e colaborar"; "Gosto do Punhobol porque ele é um jogo inclusivo, todos os alunos conseguem participar independente das características físicas"; "Ele é uma modalidade esportiva que os alunos de todos os tipos físicos conseguem jogar, promovendo a inclusão. A mudança que percebo nos alunos é que eles se organizam em campo para jogar praticar fora da escola. (Jung, 2018a, p.44).

Por essas características e motivos elencados até aqui, somado a prática cativante do Punhobol e a pouca exigência de estrutura física para que sua vivência seja possível, que escolhemos e entendemos esse esporte como uma ferramenta educacional importantíssima para difundir o desporto no ambiente escolar, de forma saudável, respeitosa, educativa e inclusiva.

Somado a isso, a proposição da Base Nacional Comum Curricular (BNCC) e do Documento Orientador Curricular do Território Riograndino (DOCTRG) preveem o trabalho com os diferentes esportes de rede divisória e parede nos $8^{\circ}$ e $9^{\circ}$ anos do ensino fundamental (Brasil, 2017; Prefeitura Municipal do Rio Grande, 2019) sendo o Punhobol uma ótima opção para os/as docentes desenvolverem e explorarem essa modalidade no âmbito escolar, ampliando o repertório motor e cultural dos/as estudantes, promovendo conhecimentos para além daquelas modalidades esportivas tradicionais trabalhadas normalmente, como a exemplo do voleibol.

\section{Caminhos Metodológicos}

Os caminhos metodológicos adotados buscam uma aproximação com as pesquisas de caráter descritivo com viés qualitativo, as quais, apresentam como característica a descrição de determinadas populações ou fenômenos (Gil, 2008).

A aproximação com o contexto investigado se deu a partir da busca documental. De acordo com Gil (2008), a pesquisa documental, em termos de seus procedimentos, é semelhante à pesquisa bibliográfica. No entanto, dela se diferencia quanto à natureza das fontes consultadas, pois utiliza materiais que ainda não receberam tratamento analítico. Na presente 
investigação, foi realizada uma visitação ao site da $\mathrm{SMEd}^{1}$, por meio do qual foram levantados os registros referentes às ações que envolvessem a modalidade esportiva Punhobol, publicadas entre os anos de 2013 e 2019.

A análise de dados se deu na perspectiva de Bardin (2016), com base nos elementos que compõem a análise de conteúdo. Iniciou-se com a pré-análise, realizada a partir da leitura flutuante das notícias, o que levou a definição do corpus. Na sequência, com a exploração do material, foram apontadas as unidades de registros, que levantaram ideias e temas comuns em todos os textos analisados. Já o tratamento dos resultados se deu a partir do agrupamento, por frequência e sentido, o que resultou em três categorias: Divulgações das ações em Punhobol; Resultados de ações em Punhobol realizadas no município; e Resultados de competições estaduais.

\section{Resultados e Discussão}

Ao realizar a busca no site da SMEd a partir da palavra "Punhobol" foi encontrado um total de 54 registros, os quais estão apresentados, a seguir, no Quadro 1. O primeiro registro foi realizado no ano de 2013 referente ao WorkShop de Punhobol realizado no município de Camaquã, seguido de ações desenvolvidas até o ano de 2019, os quais contemplaram Festivais, Campeonatos à nível local e estadual, tanto para crianças e adolescentes em idade escolar quanto para adultos em torneios livres.

Quadro 1. Síntese dos achados sobre Punhobol no site da SMEd.

\begin{tabular}{|c|c|c|c|c|}
\hline Ano / Categoria & $\begin{array}{c}\text { Divulgação de } \\
\text { ações }\end{array}$ & $\begin{array}{c}\text { Resultados de ações } \\
\text { municipais }\end{array}$ & $\begin{array}{c}\text { Resultados de competições } \\
\text { estaduais }\end{array}$ & $\begin{array}{c}\text { Total de ações por } \\
\text { ano }\end{array}$ \\
\hline $\mathbf{2 0 1 3}$ & 1 & 1 & - & 2 \\
\hline $\mathbf{2 0 1 4}$ & 2 & - & 2 & $\mathbf{2}$ \\
\hline $\mathbf{2 0 1 5}$ & 10 & 1 & 1 & $\mathbf{4}$ \\
\hline $\mathbf{2 0 1 6}$ & 2 & - & 2 & $\mathbf{3}$ \\
\hline $\mathbf{2 0 1 7}$ & 4 & 1 & 1 & $\mathbf{7}$ \\
\hline $\mathbf{2 0 1 8}$ & 4 & 4 & $\mathbf{7}$ & $\mathbf{9}$ \\
\hline $\mathbf{2 0 1 9}$ & 11 & 2 & $\mathbf{1 1}$ & \\
\hline Total & $\mathbf{3 4}$ & $\mathbf{9}$ & $\mathbf{5}$ & \\
\hline
\end{tabular}

Fonte: Elaborado pelos/as autores/as (2021).

Como podemos perceber no quadro 1, que apresenta uma síntese da quantidade de achados sobre Punhobol nas notícias postadas no site da SMEd, a primeira categoria, denominada de "Divulgação das ações em Punhobol", contou com um total de 34 notícias referentes a divulgação dos festivais, projetos extraclasses, abertura e encerramento de períodos de inscrição das ações realizadas, além da divulgação das tabelas de jogos.

Já a segunda categoria, denominada "Resultados de ações em Punhobol realizadas no município", compreende nove notícias referentes aos Festivais realizados pela Escola Municipal de Ensino Fundamental (EMEF) França Pinto, integração realizada entre as EMEF Antônio Carlos Lopes e EMEF Sant'Ana e apresentação dos resultados das Copas Cidade do Rio Grande de Punhobol Escolar (CCRGPE), todas realizadas no município de Rio Grande.

Por fim, a terceira categoria denominada "Resultados de competições estaduais" apresenta as 11 notícias referentes à participação dos/as estudantes riograndinos/as nas edições do Campeonato Gaúcho de Punhobol Escolar (CGPE) - em suas respectivas categorias, além dos resultados relacionados à participação em Copas e Torneios Livres, na categoria adulto, sediadas no município do Rio Grande.

A seguir descreveremos cronologicamente os achados, contextualizando de que forma o Punhobol vem conquistando seu espaço no ambiente escolar e fora dele no município do Rio Grande, além do destaque nas participações dos/as escolares no maior campeonato de Punhobol Escolar do estado do Rio Grande do Sul.

${ }^{1}$ Disponíveis no seguinte endereço eletrônico: http://www.riogrande.rs.gov.br/smed/ 


\subsection{O Punhobol na cidade de Rio Grande, os primeiros passos de uma história a ser contada}

A história do Punhobol Escolar no município de Rio Grande, como um trabalho frequente e contínuo, é recente, datada de meados de 2013. Nesse mesmo ano quatro docentes da rede municipal de Rio Grande participaram do I WorkShop de Punhobol Escolar, promovido pelo professor Tales Amorim realizado no Instituto Federal Sul-rio-grandense (IFSul) na cidade de Camaquã/RS. (SMEd, 2013a). Logo após o curso os/as docentes já se aventuraram e inseriram o Punhobol como conteúdo nas aulas de Educação Física, nas escolas em que estavam lotados/as. De pronto as escolas municipais França Pinto e Porto Seguro começaram o trabalho com o Punhobol nas aulas de Educação Física.

Assim, a modalidade, até então totalmente desconhecida pelos/as estudantes e por boa parte dos/as docentes, passou a dar seus primeiros passos nas escolas municipais de Rio Grande. Como toda novidade, o Punhobol causou muita estranheza, não só pelo jeito de jogar (um braço e mão fechada), mas também pelo nome, que até então era considerado estranho pelos/as estudantes.

Mesmo assim, devido às regras fáceis, a possibilidade de adaptação de materiais e, obviamente, pelo incentivo dado pelos/as docentes, o esporte começou a se consolidar fortemente no ambiente escolar riograndino, fato verificado devido a crescente a adesão e o interesse dos/as estudantes. Exemplo disso foi o I Festival França Pinto de Punhobol Escolar, organizado no final do ano de 2013, pela escola França Pinto, no qual participaram as escolas Porto Seguro, Antônio Carlos Lopes e a própria escola organizadora. O referido Festival não teve cunho competitivo e sim o interesse de divulgar e integrar os/as participantes por meio da prática do Punhobol. Logo nessa primeira ação foram mobilizadas cerca de 120 pessoas das comunidades escolares envolvidas no evento (SMEd, 2013b).

A partir do trabalho desenvolvido na escola Antônio Carlos Lopes no ano seguinte, Santos (2014) relata ter desenvolvido as expectativas de aprendizagens da modalidade nas três dimensões do conhecimento: conceitual, procedimental e atitudinal. Durante as aulas de Educação Física os/as estudantes tiveram a oportunidade de conhecer a origem, curiosidades e regras básicas do esporte; vivenciar a dinâmica do jogo; organizar um evento esportivo; construir uma rede de Punhobol a partir de material alternativo; respeitar as habilidades de todos e colaborar na construção das atividades (SANTOS, 2014). De acordo com Santos (2014), foi possível alcançar os resultados esperados e desenvolver um aprendizado satisfatório, que pôde ser observado durante a realização do Torneio d Punhobol, organizado pela turma de $9^{\circ}$ ano da escola.

O trabalho com a modalidade encorajou os/as estudantes da Escola Antônio Carlos Lopes a disseminar seus aprendizados com seus pares da Escola Sant'Ana. Na oportunidade houve a integração, através do Punhobol, entre aproximadamente 100 pessoas das comunidades escolares envolvidas (SMEd, 2014a).

No mesmo ano, de acordo com Cunha (2015) o Punhobol chega, enquanto conteúdo, ao Instituto Federal do Rio Grande do Sul (IFRS) Campus Rio Grande. Na época, a Educação Física era desenvolvida em oficinas, nas quais o/as estudantes se matriculavam, de acordo com seu interesse ou de acordo com o horário que melhor se encaixasse em sua grade de disciplinas. Inicialmente, com receio da não aceitação ou procura pela Oficina de Punhobol, o professor propôs, para o $1^{\circ}$ semestre, uma oficina chamada "Punhobol e Vôlei", tendo o voleibol como uma "isca" aos/às possíveis matriculados/as, já que, até então, o Punhobol era uma prática desconhecida e correria o risco não haver procura.

No entanto, assim como nas escolas municipais de ensino fundamental, o Punhobol foi tão atrativo aos/às inscritos/as que o voleibol acabou praticamente não sendo vivenciado nas aulas realizadas na referida oficina. Com isso, tendo em vista o interesse acentuado dos/as estudantes, no $2^{\circ}$ semestre foi oferecida uma Oficina exclusivamente de Punhobol, a qual passou a ter uma procura relevante (Cunha, 2015).

Paralelo a isso, em algumas escolas municipais, como o Punhobol não era mais uma novidade, a demanda aumentou e as aulas de Educação Física passaram a não dar conta do interesse crescente e do desenvolvimento técnico dos/as estudantes. Tais circunstâncias deram ensejo às escolas França Pinto e Porto Seguro proporem Projetos envolvendo a modalidade no 
contra turno escolar (SMEd, 2015h).

Esse tempo extra para a prática do Punhobol, assim como, consequentemente, o aumento do nível técnico dos/as estudantes, motivou as escolas riograndinas a participarem do I Campeonato Gaúcho de Punhobol Escolar (CGPE), no ano de 2014, o qual teve uma etapa na cidade de Novo Hamburgo e outra etapa na cidade de Camaquã (SMEd, 2014b). O Campeonato Gaúcho de Punhobol Escolar foi uma idealização dos Projetos "Legal é... Punhobol na Escola e na Comunidade" que acontece no município de Novo Hamburgo e do "Projeto Punhobol: do IFSul-Camaquã para todos" do município de Camaquã, sendo aprovado e fidelizado pela Federação Gaúcha de Punhobol/Fistball e Confederação Brasileira de Desportos Terrestres (SMEd, 2019a).

Além disso, neste mesmo ano, foi realizado nas dependências do Centro Esportivo do Sport Club Rio Grande o II Festival de Punhobol da escola França Pinto (SMEd, 2014c), o qual mobilizou estudantes das escolas Antônio Carlos Lopes, Clemente Pinto e França Pinto. O evento proporcionou que os/as participantes assistissem partidas oficiais e interagissem com jogadores/as amadores/as experientes da modalidade, já que o município sediou, concomitantemente ao Festival a $5^{\mathrm{a}}$ rodada da $11^{\text {a }}$ Copa Livre de Punhobol. A Copa Livre de Punhobol é uma competição adulta que une equipes de diversas regiões do Estado, femininas e masculinas, e pela primeira vez, nos onze anos de história da Copa, uma cidade do extremo sul foi sede dessa competição (SMEd, 2014d).

Segundo Cunha (2015) foi no ano de 2015 que o IFRS - Campus Rio Grande ampliou a prática do Punhobol, tendo a necessidade de expandir as ações para além das aulas de educação física, sendo necessário promover um projeto no contra turno escolar. No mesmo ano, a escola França Pinto promove o III Festival de Punhobol, que tomou uma dimensão superior à esperada, tendo que ser realizado no Centro Esportivo da Universidade Federal do Rio Grande (FURG), pois com a abertura de inscrições (SMEd, 2015a) se teve a mobilização de cerca de 120 estudantes de nove instituições de ensino do município (SMEd, 2015b).

Além da anfitriã França Pinto, participaram também as escolas EMEF Clemente Pinto, EMEF Porto Seguro, EMEF Wanda Rocha, EMEF Peixoto Primo, EMEF Helena Small, EMEF Antônio Carlos Lopes, IFRS e Cesam (SMEd, 2015b). Somado às escolas rio-grandinas, o IFSul/Camaquã também esteve representado pelos estudantes e pelo professor de Educação Física Tales Amorim, que é considerado um dos maiores incentivadores do Punhobol escolar no Brasil.

De forma a compartilhar suas experiências sobre a modalidade, o professor Tales Amorim foi convidado pela SMEd de Rio Grande, por meio da Assessoria de Educação Física, a ministrar uma oficina intitulada "Punhobol na escola: mais oportunidades, mais alegrias“aos/às docentes de Educação Física da rede pública de ensino e interessados/as na temática (SMEd, 2015c; SMEd, 2015d). Os/As professores/as participantes tiveram a oportunidade de ampliar seus conhecimentos sobre o histórico e o panorama do esporte no mundo, no Brasil e na escola, além de conhecer o funcionamento básico, as regras e os fundamentos técnicos e táticos do Punhobol. O encontro proporcionou um momento de reflexão sobre a Educação Física escolar e o papel do/a docente, finalizando com uma prática que focou nos princípios básicos do jogo (SMEd, 2015g).

A partir de 2015 o Festival de Punhobol Escolar toma grande proporção e as escolas voltaram a participar do II CGPE. Na ocasião, devido à ascensão rápida do Punhobol Escolar riograndino e devido ao interesse que começava a surgir em outras escolas, como se percebeu pelo número de inscritos/as no III Festival, a I Etapa do CGPE 2015, que aconteceu em Novo Hamburgo, contou com a participação de quatro equipes escolares de Rio Grande (SMEd, 2015i)

A realização da II Etapa do CGPE 2015, em Rio Grande, foi propulsora para a modalidade (SMEd, 2015j; SMEd, 2015k; SMEd, 2015l). A partir desse evento, o qual mobilizou a participação de seis escolas municipais e o Instituto Federal, o município passou a ser reconhecido como a cidade com o maior número de escolas participantes do CGPE. Provavelmente, seja também a cidade Brasileira com maior número de escolares praticantes, já que a região Sul é reconhecidamente a que possui o maior número de punhobolistas dessa modalidade (SMEd, 2015m). 
Ainda em 2015, a Assessoria Pedagógica de Educação Física da SMEd reuniu os/as docentes do componente curricular com objetivo de definir, de forma coletiva, o Plano de Estudos dos Anos Finais (Prefeitura do Rio Grande, 2015). Na oportunidade, como uma grata surpresa, a modalidade Punhobol foi incluída na categoria dos esportes não tradicionais a ser desenvolvida nas aulas de Educação Física escolar na rede municipal de ensino.

O ano de 2016 foi extremamente promissor para o Punhobol Escolar riograndino. Houve a manutenção dos campeonatos já tradicionais, como o Festival França Pinto que se encontrava na sua IV edição (SMEd, 2016a) e a participação de quatro escolas riograndinas (França Pinto, Porto Seguro, CAIC e IFRS) na III Edição do CGPE (SMEd, 2016b). Os/As estudantes do IFRS tiveram a oportunidade de participar do XXI Torneio Internacional de Punhobol, realizado na cidade de Novo Hamburgo. Na ocasião, vindo a disputar partidas contra clubes tradicionais de outros países, como Argentina e Colômbia, além de ter contato com a seleção brasileira sub-18, que aproveitou o torneio como preparação para o mundial. Dessa forma, os/as estudantes puderam adquirir experiência no esporte e representar a instituição escolar em meio a grandes clubes de destaque no cenário nacional e internacional do Punhobol dessa faixa etária (ISRS, 2016).

O grande passo na jornada da consolidação do Punhobol no município do Rio Grande foi dado em 2016, em virtude da organização de um novo evento municipal, denominado I Copa Cidade do Rio Grande de Punhobol Escolar (CCRGPE). Evento esse constituído após a percepção dos/as docentes, que trabalhavam com a modalidade, de que o nível técnico dos/as estudantes já estava um patamar acima de quando se iniciou o trabalho com Punhobol na cidade. Outro fator determinante foi o aumento expressivo no número de escolas que haviam inserido a modalidade como conteúdo nas aulas de Educação Física.

Diferentemente dos Festivais, a Copa teve cunho competitivo e foi dividida em três categorias, sub-13, sub-15 e sub17, nos naipes masculino e feminino. Na sua primeira edição contou com a participação de 11 escolas e 36 equipes, tendo sido realizado de forma Indoor no Centro Esportivo do SESI (SMEd, 2016c).

Na sequência, ainda no ano de 2016, em levantamento realizado pela Assessoria de Educação Física da SMEd junto às instituições escolares municipais, solicitada pelo professor Tales Amorim, foi constatado que vinte escolas municipais de Rio Grande utilizavam o Punhobol como instrumento pedagógico, seja nas aulas de Educação Física ou em projetos extraclasse (SMEd, 2017e). Fato este que tornou Rio Grande um dos municípios que mais estimula a prática desse esporte na Escola, tanto no Estado quanto no país.

Em 2017 os esforços estavam centralizados na realização da II CCRGPE, o qual ocorreu no Centro Esportivo do SESI e mobilizou 11 instituições de ensino, sendo nove Escolas da Rede Municipal (EMEFs Admar Corrêa, Ana Neri, Cidade do Rio Grande/CAIC, Dolores Garcia, França Pinto, Frederico Ernesto Buchholz, Peixoto Primo, Porto Seguro e Wanda Rocha Martins), o IFRS/Rio Grande e uma Escola da Rede Privada - Cristo Rei (SMEd, 2017a; SMEd, 2017b; SMEd, 2017c). Essa edição, em especial, agregou estudantes e professores/as de quatro outras escolas (Wanda Rocha, Admar Corrêa, Dolores Garcia e Cristo Rei), que ainda não haviam tido contato anterior com a modalidade, possibilitando assim um momento promissor com esse esporte que acolhe, agrega e educa.

O município, nesse ano, ganha visibilidade estadual quando é citado pelo atleta e treinador das equipes femininas da Sogipa, clube tradicional e um dos pioneiros dessa prática no do Estado do Rio Grande do Sul, Carlos Alberto Fonseca Veneroso, como um polo de iniciação do Punhobol Escolar, junto a outras três cidades. "Hoje temos, principalmente, em Novo Hamburgo, Camaquã, Cristal e Rio Grande, polos de iniciação do punhobol na escola. Acredito que aí está uma ferramenta importante para que o Punhobol dê um salto importante dentro do Estado" (SMEd, 2017e, s.p).

A Sociedade Ginástica de Novo Hamburgo foi palco da quarta edição do CGPE, que contou com a participação de cerca de 450 estudantes, representando as cidades de Novo Hamburgo, Ivoti, Campo Bom, Dois Irmãos, Camaquã, Cristal e Rio Grande. Por mais um ano consecutivo, o município de Rio Grande foi representado pelas escolas EMEF Cidade de Rio Grande, EMEF França Pinto, EMEF Porto Seguro e IFRS/Rio Grande, o que representou a maior delegação e trouxe resultados 
expressivos para a comunidade escolar (SMEd, 2017g).

Os resultados alcançados nessa edição foram: EMEF Cidade do Rio Grande (CAIC) $2^{\circ}$ lugar no Sub-12 masculino, $4^{\circ}$ lugar no Sub-12 feminino, $3^{\circ}$ lugar no Sub-14 masculino e $4^{\circ}$ lugar no Sub-14 feminino; EMEF Porto Seguro $2^{\circ}$ lugar no Sub14 feminino; EMEF França Pinto ficou na $4^{\mathrm{a}}$ colocação no Sub-18 masculino; IFRS/Rio Grande consagrou-se vice-campeão na categoria Sub-18 masculino (SMEd, 2017f; SMEd, 2017g).

O ano de 2018 foi marcado pela realização da quinta edição do CGPE realizada na cidade de Pelotas, no Parque Esportivo e Recreativo Lobão. A edição contou com a participação de 502 alunos/as divididos/as em 66 equipes, os quais disputaram 134 jogos. Nessa edição houve a participação de 14 escolas que representaram as cidades de Camaquã, Cristal, Canguçu, Dois Irmãos, Pelotas, Rio Grande e Novo Hamburgo. Na ocasião, a cidade de Rio Grande foi representada pelas Escolas Municipais de Ensino Fundamental Cidade do Rio Grande/CAIC, França Pinto e Porto Seguro, além das equipes do IFRS/Rio Grande. Essa representação fez com que, por mais um ano consecutivo, Rio Grande fosse reconhecido como o município com máxima representatividade no maior evento de Punhobol do estado do RS (SMEd, 2018a).

Os resultados dessa edição foram os mais expressivos alcançados até então, pois a EMEF Porto Seguro consagrou-se campeã na categoria Sub-12 feminina, vice-campeã nas categorias sub-12 masculina e sub-14 feminina, além de $4^{\circ}$ lugar no sub-14 masculino. A EMEF Cidade do Rio Grande foi vice-campeã na categoria Sub14 masculino e $4^{\circ}$ lugar no Sub-14 feminino. E as equipes do IFRS ficaram em $3^{\circ}$ e $4^{\circ}$ lugares na categoria Sub-18 masculino e em $4^{\circ}$ lugar na Sub-18 feminino (SMEd, 2018a).

A terceira edição da CCRGPE aconteceu no Centro de Treinamento Parque da Bola, localizado no Partage Shopping, e contou com a participação de oito escolas, nas três categorias sub-13, sub-15 e sub-17. Foram cerca de 300 participantes divididos/as em 36 equipes (19 masculinas e 17 femininas), que disputaram 84 jogos (SMEd, 2018b; SMEd, 2018c; SMEd, 2018d). Nessa edição as expectativas foram superadas, pois ao invés de realizar o evento no ginásio, de forma indoor, foi estabelecida a parceria com o Partage Shopping e com o Parque da Bola para realização dos jogos em um ambiente aberto, o mais próximo da realidade do esporte (SMEd, 2018h). A chamada para que a comunidade riograndina acompanhasse os jogos foi realizada por meio de notícia vinculado no site da SMEd (2018e) e na rádio local. Os resultados das partidas ao longo dos dias de jogos também foram vinculados nas mesmas mídias (SMEd, 2018f; SMEd, 2018g).

A terceira CCRGPE contou com um número menor de escolas participantes em comparação aos anos anteriores, uma vez que a data de realização do evento coincidiu com outras atividades escolares. Apesar disso, como ponto positivo houve a mobilização de três escolas, as quais participaram pela primeira vez da competição (SMEd, 2018i). Desde então, as escolas municipais EMEF Cipriano Porto Alegre e Zenir de Souza Braga, e a estadual, EEEM Lilia Neves, são adeptas ao esporte, vindo a somar àquelas que já desenvolviam a modalidade em seus currículos escolares.

Finalizando essa linha do tempo, chegamos ao ano de 2019, onde o $6^{\circ}$ CGPE foi realizado em um novo formato, a partir de três etapas classificatórias e uma final. As classificatórias foram realizadas na região Metropolitana (que ocorreu em Novo Hamburgo e contemplou estudantes de Guaíba e cidades mais ao norte do estado), na região Centro (que aconteceu em Camaquã e contemplou escolares de Tapes até Cristal) e a região Sul (que aconteceu em Rio Grande e acolheu estudantes de São Lourenço e cidades mais ao Sul do estado). O município do Rio Grande foi agraciado com a realização da etapa Sul da maior competição de Punhobol Escolar do Brasil, como forma de reconhecimento às participações de sucesso nas edições anteriores da competição (SMEd, 2019a; SMEd, 2019b).

A etapa Sul do $6^{\circ}$ CGPE contou com a participação de 12 instituições escolares, sendo dez de Rio Grande (sete municipais, duas estaduais e o IFRS/Rio Grande) e duas de Pelotas. O panorama geral mostrou que o evento contou com 45 equipes inscritas (28 masculinas e 17 femininas) e propôs a realização de 85 partidas, distribuídas nos dois dias de jogos (SMEd, 2019e; SMEd, 2019f; SMEd, 2019g). 
A etapa final do $6^{\circ}$ CGPE aconteceu no município de Camaquã e foi realizada com as equipes campeãs e vicecampeãs de cada categoria-naipe, classificadas nas etapas regionais (SMEd, 2019c; SMEd, 2019d). A Região Sul foi representada por 15 equipes, das quais 14 foram de instituições escolares de Rio Grande. As equipes das escolas Cipriano Porto Alegre, Zenir de Souza Braga e Lilia Neves que tiveram seu primeiro contato com o esporte apenas no ano de 2018 garantiram sua participação na competição de nível estadual, além das equipes do Porto Seguro, CAIC e IFRS/Rio Grande, as quais já representaram o município em edições anteriores da competição (SMEd, 2019h).

Já a IV CCRGPE teve na sua divulgação inicial a indicação de acontecimento no Centro Esportivo da FURG (SMEd,2019i), mas devido a previsão do tempo os jogos acabaram sendo transferidos para o Centro Esportivo do SESI (SMEd, 2019k). Essa edição da Copa contou com a participação de dez instituições escolares divididas nas três categorias contempladas na competição: sub13, sub15 e sub18 (SMEd, 2019j). A competição mobilizou um total de 38 equipes e, aproximadamente, 300 participantes (SMEd, 20191; SMEd, 2019m). Nesse ano não houve a participação de nenhuma escola pela primeira vez, fortalecendo a consolidação dessa prática naquelas instituições escolares que já desenvolvem ações em Punhobol há, no mínimo, um ano.

Um marco no ano de 2019 foi a realização do I Torneio Rio-grandino de Punhobol. O Torneio contemplou a categoria Livre (sem limite de idade) e o naipe misto (equipes com atletas dos dois gêneros, masculino e feminino) e foi idealizado para fomentar a prática do Punhobol entre ex-alunos/as, acadêmicos/as, professores/as e comunidade em geral, que devido à idade não estavam aptos/as a participar do torneio em nível escolar, além de não ter eventos esportivos para jogar (SMEd, 2019p). A proposição dos jogos de forma mista foi para promover a integração por meio do esporte (SMEd, 2019n). Na oportunidade tivemos a participação de seis equipes, sendo quatro delas do município do Rio Grande e composta, em sua maioria, pelos/as ex-alunos/as dos Projetos das escolas e que atuam como mediadores/as na CCRGPE, além de receber duas equipes da cidade de Camaquã, compostas por ex-alunos/as do Projeto Punhobol: do IFSul-Camaquã para todos (SMEd, 2019n).

Ao longo desses anos, pudemos perceber que o Punhobol conquistou um espaço de destaque no município de Rio Grande com a inclusão da modalidade como conteúdo das aulas de Educação Física, conquistando carga horária em Projetos Extraclasses, além da efetivação de Festivais e Torneios escolares e livres. A visibilidade das ações realizadas em Rio Grande foi tão significativa, tanto a nível municipal quanto regional, que possibilitou que o município fosse sede de competições importantes da modalidade. Vale ressaltar a evolução técnica dos/as estudantes rio-grandinos/as, os/as quais passaram a se destacar no CGPE, instigando a efetivação de competições escolares, além do Torneio Livre e Misto, realizado para suprir a demanda daqueles ex-estudantes que não poderiam mais participar das competições escolares.

\section{Considerações Finais}

Com a recente implementação do Punhobol nas escolas de Rio Grande, há pouco mais de seis anos, considerando as aulas de Educação Física, Projetos Extraclasse e competições esportivas realizadas tanto no município quanto a nível estadual, percebemos das notícias publicadas no site da SMEd e apresentadas neste artigo de forma cronológica, as diversas ações realizadas, integrando as escolas do município com outras comunidades, grupos e instituições.

Além disso, a organização e participação em eventos esportivos, como os Festivais e Copas, demonstram o quão inserido esse esporte está na Educação Física e na cultura escolar como um todo, o que foi observado pela mobilização de diferentes instituições de ensino participantes nas ações relatadas. Esse fato reforça o potencial do Punhobol enquanto um esporte possível de ser desenvolvido no contexto escolar, de fácil adaptação e que proporciona uma prática prazerosa e inclusiva.

Com isso, percebemos que, apesar de relativamente recente, o trabalho realizado em parceria com os/as estudantes e docente do município de Rio Grande tem feito com que o Punhobol deixe de ser um esporte totalmente desconhecido e se torne 
uma prática popular em uma parcela considerável de escolas, escrevendo assim, a história de sucesso dessa prática consolidada a nível escolar.

Por fim, destacamos a importância de que novas investigações com foco no entendimento de como tem se dado a inserção tanto do Punhobol quanto de outros esportes não tradicionais nas aulas de educação física escolar sejam realizadas. Além disso, sinalizamos como sugestão de pesquisas futuras averiguar como tem sido a expansão da prática do Punhobol nas demais cidades da região sul do estado do RS.

\section{Referências}

Bardin, L. (2016). Análise de conteúdo. Tradução de Luiz Antero Reto e Augusto Pinheiro. Edições 70.

Brasil. (2017). Ministério da Educação. Base Nacional Comum Curricular. http://basenacionalcomum.mec.gov.br/.

Cunha, L.C. (2015). Punhobol: de uma prática desconhecida à popularização em escolas de Rio Grande/RS. Revista Didática Sistêmica, Edição Especial, p. 79-90. https://periodicos.furg.br/redsis/article/view/5900.

Gil, A. C. (2008). Como elaborar projetos de pesquisa. (4a ed.). Atlas.

Heck, D. A. P.; Heck, J. L. (2014). Punhobol: cartilha de regras. (2a ed). Projeto Legal é Punhobol nas Escolas.

Instituto Federal de Educação, Ciência e Tecnologia do Rio Grande do Sul - Câmpus Rio Grande. (2016). Equipe de Punhobol do Campus Rio Grande participa de torneio internacional. https://riogrande.ifrs.edu.br/site/conteudo.php?cat=5\&sub=2582.

Jung, L. G. (2018). Percepção de professores e alunos sobre a prática do Punhobol na educação física escolar. (Tese de Doutorado) — Programa de PósGraduação em Educação Física, Escola Superior de Educação Física, Universidade Federal de Pelotas.

Jung, L. G. (2018a). Punhobol na Educação Física Escolar. PoD.

Prefeitura Municipal do Rio Grande. (2015). Plano de Estudos dos Anos Finais. http://www.riogrande.rs.gov.br/smed/wp-content/uploads/2016/12/20161223plano_de_estudos_finais.pdf.

Prefeitura Municipal do Rio Grande (2019). Documento Orientador Curricular do Território Riograndino. https://www.riogrande.rs.gov.br/smed/externo/20200324-doc_ensino_fundamental.pdf.

Santos, L. L. (2014). Punhobol na escola. Revista didática sistêmica. Edição Especial, p.344. https://periodicos.furg.br/redsis/article/view/5244/3238.

Secretaria de Município da Educação. (2013a). MUNICÍPIO de Rio Grande é representado no $1^{o}$ Workshop de Punhobol Escolar do IFSul Camaquã. http://www.riogrande.rs.gov.br/smed/?p=7558.

Secretaria de Município da Educação. (2013b). I FESTIVAL de Punhobol da EMEF França Pinto. http://www.riogrande.rs.gov.br/smed/?p=8843.

Secretaria de Município da Educação. (2014a). PUNHOBOL é disseminado nos Núcleos de Rio Grande - Rede RS. http://www.riogrande.rs.gov.br/smed/?p=10871.

Secretaria de Município da Educação. (2014b). MUNICÍPIO do Rio Grande é representado no I Circuito Gaúcho de Punhobol em Novo Hamburgo. http://www.riogrande.rs.gov.br/smed/?p=10949.

Secretaria de Município da Educação. (2014c). FESTIVAL de Punhobol acontecerá amanhã. http://www.riogrande.rs.gov.br/smed/?p=11255.

Secretaria de Município da Educação. (2014d). RIO GRANDE sediou etapa da $11^{a}$ Copa Livre de Punhobol Amador. http://www.riogrande.rs.gov.br/smed/?p=11300.

Secretaria de Município da Educação. (2015a). INSCRIÇÕES para o III Festival de Punhobol da EMEF França Pinto vão até dia 4 de maio. http://www.riogrande.rs.gov.br/smed/?p=13024.

Secretaria de Município da Educação. (2015b). III FESTIVAL de Punhobol da EMEF França Pinto reuniu cerca de 120 alunos. http://www.riogrande.rs.gov.br/smed/?p=13448.

Secretaria de Município da Educação. (2015c). SMED promove Oficina "Punhobol na escola: mais oportunidades, mais alegrias". http://www.riogrande.rs.gov.br/smed/?p=13353.

Secretaria de Município da Educação. (2015d). OFICINA de Punhobol. http://www.riogrande.rs.gov.br/smed/?page_id=13356.

Secretaria de Município da Educação. (2015e). INSCRIÇÕES para Oficina "Punhobol na escola: mais oportunidades, mais alegrias" encerram hoje. http://www.riogrande.rs.gov.br/smed/?p=13600.

Secretaria de Município da Educação. (2015f). PRORROGADO até quarta-feira, 27, o período de inscrições para Oficina de Punhobol da SMEd. http://www.riogrande.rs.gov.br/smed/?p=13618.

Secretaria de Município da Educação. (2015g). SMED realizou Oficina de Punhobol no dia 29. http://www.riogrande.rs.gov.br/smed/?p=13780. 
Secretaria de Município da Educação. (2015h). ALUNOS da EMEF França Pinto praticam Punhobol desde 2013. http://www.riogrande.rs.gov.br/smed/?p=15333.

Secretaria de Município da Educação. (2015i). ESCOLAS da Rede Municipal participaram da $1^{a}$ Etapa do Campeonato Gaúcho de Punhobol Escolar 2015, em Novo Hamburgo. http://www.riogrande.rs.gov.br/smed/?p=15432.

Secretaria de Município da Educação. (2015j). JÁ estão abertas as inscrições para o II Campeonato Gaúcho de Punhobol Escolar. http://www.riogrande.rs.gov.br/smed/?p=15107.

Secretaria de Município da Educação. (2015k). 2 ${ }^{a}$ ETAPA do “Campeonato Gaúcho de Punhobol Escolar 2015 ” acontecerá no dia 29. http://www.riogrande.rs.gov.br/smed/?p=15642.

Secretaria de Município da Educação. (20151). $2^{a}$ ETAPA do Campeonato Gaúcho de Punhobol Escolar acontece nesta quinta-feira, 2. http://www.riogrande.rs.gov.br/smed/?p=15921.

Secretaria de Município da Educação. (2015m). RIO GRANDE sediou a $2^{a}$ etapa do II Campeonato Gaúcho de Punhobol Escolar 2015. http://www.riogrande.rs.gov.br/smed/?p=16080.

Secretaria de Município da Educação. (2016a). EMEF França Pinto promoverá "IV Festival de Punhobol" no dia 30. http://www.riogrande.rs.gov.br/smed/?p=17864.

Secretaria de Município da Educação. (2016b). ESCOLAS de Rio Grande participaram do "III Campeonato Gaúcho de Punhobol Escolar". http://www.riogrande.rs.gov.br/smed/?p=19114.

Secretaria de Município da Educação. (2016c). ABERTURA da "I Copa Cidade do Rio Grande de Punhobol Escolar" aconteceu nesta terça-feira, 04. http://www.riogrande.rs.gov.br/smed/?p=19223.

Secretaria de Município da Educação. (2017a). PERÍODO de inscrições para a "2a Copa Cidade do Rio Grande de Punhobol Escolar" vai até o dia 22. http://www.riogrande.rs.gov.br/smed/?p=23265.

Secretaria de Município da Educação. (2017b). PERÍODO de inscrições para a "2a Copa Cidade do Rio Grande de Punhobol Escolar” vai até o dia 22. http://www.riogrande.rs.gov.br/smed/?p=23166.

Secretaria de Município da Educação. (2017c). SMED divulga Tabelas dos Jogos da "2a Copa Cidade do Rio Grande de Punhobol Escolar". http://www.riogrande.rs.gov.br/smed/?p=23483.

Secretaria de Município da Educação. (2017d). CERIMÔNIA de Abertura da "2 a Copa Cidade do Rio Grande de Punhobol Escolar" acontecerá nesta quartafeira, dia 04. http://www.riogrande.rs.gov.br/smed/?p=23493.

Secretaria de Município da Educação. (2017e). $2^{a}$ COPA Cidade do Rio Grande de Punhobol Escolar ganha destaque no Estado. http://www.riogrande.rs.gov.br/smed/?p=23716.

Secretaria de Município da Educação. (2017f). ESCOLAS da Rede Municipal destacaram-se na $4^{a}$ edição do "Campeonato Gaúcho de Punhobol Escolar". http://www.riogrande.rs.gov.br/smed/?p=22210.

Secretaria de Município da Educação. (2017g). EMEF Cidade do Rio Grande/CAIC participa do Campeonato Gaúcho de Punhobol Escolar. http://www.riogrande.rs.gov.br/smed/?p=22141.

Secretaria de Município da Educação. (2018a). Escolas da Rede Municipal participaram da $5^{a}$ edição do Campeonato Gaúcho de Punhobol Escolar. https://www.riogrande.rs.gov.br/smed/?p=28356.

Secretaria de Município da Educação. (2018b). "3a Copa Cidade do Rio Grande de Punhobol Escolar”: Periodo de inscrições já iniciou. https://www.riogrande.rs.gov.br/smed/?p=29189.

Secretaria de Município da Educação. (2018c). Período de inscrições para a "3a Copa Cidade do Rio Grande de Punhobol Escolar" encerra nesta quartafeira, $1^{o}$. https://www.riogrande.rs.gov.br/smed/?p=29432.

Secretaria de Município da Educação. (2018d). SMEd divulga Tabelas dos Jogos da "3a Copa Cidade do Rio Grande de Punhobol Escolar". https://www.riogrande.rs.gov.br/smed/?p=29616.

Secretaria de Município da Educação. (2018e). "3a Copa Cidade do Rio Grande de Punhobol Escolar” inicia nesta segunda-feira, dia 12. https://www.riogrande.rs.gov.br/smed/?p=29698.

Secretaria de Município da Educação. (2018f). "3a Copa Cidade do Rio Grande de Punhobol Escolar” já tem os primeiros vencedores. https://www.riogrande.rs.gov.br/smed/?p=29721.

Secretaria de Município da Educação. (2018g). "3 $3^{a}$ Copa Cidade do Rio Grande de Punhobol Escolar”: SMEd divulga resultados da Categoria Sub-15. https://www.riogrande.rs.gov.br/smed/?p=29775.

Secretaria de Município da Educação. (2018h). “3a Copa Cidade do Rio Grande de Punhobol Escolar” contou com cerca de 300 participantes. https://www.riogrande.rs.gov.br/smed/?p=29843.

Secretaria de Município da Educação. (2018i). $3^{a}$ Copa Cidade do Rio Grande de Punhobol Escolar. https://www.riogrande.rs.gov.br/smed/?page_id=29187.

Secretaria de Município da Educação. (2019a). Rio Grande sediará a Etapa Sul do $6^{\circ}$ Campeonato Gaúcho de Punhobol Escolar. https://www.riogrande.rs.gov.br/smed/?p=34236. 
Research, Society and Development, v. 11, n. 1, e47011125270, 2022

(CC BY 4.0) | ISSN 2525-3409 | DOI: http://dx.doi.org/10.33448/rsd-v11i1.25270

Secretaria de Município da Educação. (2019b). Cidade do Rio Grande sediará Etapa Sul do " $6{ }^{\circ}$ Campeonato Gaúcho de Punhobol Escolar" nos dias $1{ }^{\circ}$ e 02 de agosto. https://www.riogrande.rs.gov.br/smed/?p=34762.

Secretaria de Município da Educação. (2019c). Período de inscrições para a Etapa Sul do $6^{\circ}$ Campeonato Gaúcho de Punhobol Escolar vai até o dia 15. https://www.riogrande.rs.gov.br/smed/?p=34437.

Secretaria de Município da Educação. (2019d). Etapa Sul do $6^{\circ}$ Campeonato Gaúcho de Punhobol Escolar: Período de inscrições encerra na próxima segunda-feira, dia 15. https://www.riogrande.rs.gov.br/smed/?p=34603.

Secretaria de Município da Educação. (2019e). SMEd divulga Tabelas dos Jogos da "Etapa Sul do 6 Campeonato Gaúcho de Punhobol Escolar". https://www.riogrande.rs.gov.br/smed/?p=34682.

Secretaria de Município da Educação. (2019f). Etapa Sul do " $6^{\circ}$ Campeonato Gaúcho de Punhobol Escolar" acontece em Rio Grande nos dias 1 e e 02 de agosto. https://www.riogrande.rs.gov.br/smed/?p=34724.

Secretaria de Município da Educação. (2019g). "Etapa Sul do $6^{\circ}$ Campeonato Gaúcho de Punhobol Escolar": Primeiro dia de Competição teve jogos das categorias Sub-12 e Sub-14. https://www.riogrande.rs.gov.br/smed/?p=34790.

Secretaria de Município da Educação. (2019h). Cidade do Rio Grande foi Sede da Etapa Sul do "6" Campeonato Gaúcho de Punhobol Escolar". https://www.riogrande.rs.gov.br/smed/?p=34910.

Secretaria de Município da Educação. (2019i). Periodo de inscrições para a "IV Copa Cidade do Rio Grande de Punhobol Escolar" encerra nesta sexta-feira, 11. https://www.riogrande.rs.gov.br/smed/?p=36223.

Secretaria de Município da Educação. (2019j). SMEd divulga Tabelas dos Jogos da "IV Copa Cidade do Rio Grande de Punhobol Escolar". https://www.riogrande.rs.gov.br/smed/?p=36340.

Secretaria de Município da Educação. (2019k). "IV Copa Cidade do Rio Grande de Punhobol Escolar" inicia nesta quinta-feira, dia 17. https://www.riogrande.rs.gov.br/smed/?p=36367.

Secretaria de Município da Educação. (20191). "IV Copa Cidade do Rio Grande de Punhobol Escolar" já tem os primeiros vencedores. https://www.riogrande.rs.gov.br/smed/?p=36424.

Secretaria de Município da Educação. (2019m). "IV Copa Cidade do Rio Grande de Punhobol Escolar" encerrou na última sexta-feira, 18. https://www.riogrande.rs.gov.br/smed/?p=36529.

Secretaria de Município da Educação. (2019n). SMEd divulga tabela de jogos do "I Torneio Rio-grandino de Punhobol (Livre e Misto)". https://www.riogrande.rs.gov.br/smed/?p=36391.

Secretaria de Município da Educação. (2019o). "I Torneio Rio-grandino de Punhobol (Livre e Misto)" acontece neste sábado, 19. https://www.riogrande.rs.gov.br/smed/?p=36487.

Secretaria de Município da Educação. (2019p). "I Torneio Rio-grandino de Punhobol (Livre e Misto)" recebeu duas equipes de Camaquã. https://www.riogrande.rs.gov.br/smed/?p=36613.

Silva, P. R. L; Montiel, F. C; Amorim, T. E. C; Garcia, R. C. G; Botelho, V. H; Pinheiro, E. S., \& Afonso, M. R. (2020). Motivações para a prática da modalidade Punhobol o lazer. Revista Licere, 23(4), p. 230-248. https://periodicos.ufmg.br/index.php/licere/article/view/26679/20380.

Vago, T. M. (1996). O "esporte na escola" e o "esporte da escola": da negação radical para uma relação de tensão permanente. Revista Movimento, 3(5), p.4 17. https://seer.ufrgs.br/Movimento/article/viewFile/2228/936. 